J. Lake Sci. (湖泊科学), 2015, 27(2):258-265

http : //www. jlakes.org. E-mail : jlakes@niglas.ac.cn

(C) 2015 by Journal of Lake Sciences

\title{
太湖浮游植物中重金属含量的季节变化特征及湖区差异
}

\author{
王颢雪 ${ }^{1,2}$, 王沛芳 ${ }^{1,2 * *}$, 王 超 ${ }^{1,2}$, 刘佳佳 ${ }^{1,2}$, 王壼喆 ${ }^{1,2}$ \\ (1: 河海大学浅水湖泊综合治理与资源开发教育部重点实验室,南京 210098) \\ (2: 河海大学环境学院,南京 210098)
}

\begin{abstract}
摘 要: 近年来随着社会经济的发展, 排人太湖的污水中重金属含量不断增加, 为研究太湖浮游植物中重金属的污染状 况, 分别于 2009 年春季 (4 月)、夏季 (7 月) 和冬季(12 月)对太湖不同湖区展开调查, 通过 HCA 聚类分析和 Pearson 相关 分析探讨不同湖区浮游植物中重金属含量的季节变化, 并与优势藻种进行 CCA 分析, 对浮游植物重金属与各藻种关系进 行初步探讨. 结果表明: 太湖浮游植物中重金属的含量大小为: $\mathrm{Zn}>\mathrm{Mn}>\mathrm{Pb}>\mathrm{Cu}>\mathrm{Ni}>\mathrm{Cr}>\mathrm{As}>\mathrm{Cd}>\mathrm{Hg}$, 其中 $\mathrm{Zn} 、 \mathrm{Cu}$ 、 $\mathrm{Mn} 、 \mathrm{~Pb} 、 \mathrm{Ni}$ 的季节变化明显, $\mathrm{Zn}$ 和 $\mathrm{Cu} 、 \mathrm{~Pb} 、 \mathrm{Ni} 、 \mathrm{Cr}$ 之间的相关系数很高且具有同源性. 通过对比不同湖区, 发现北部梅梁湾 的浮游植物重金属含量较高, 东太湖和湖心区含量均低于沿岸湖区. CCA 分析表明春季重金属与优势藻种呈正相关,而 夏季和冬季二者呈负相关. 三季中重金属与蓝藻和绿藻的相关性最高, 与隐藻的相关性最低. 蓝藻中, 重金属与铜绿微囊 藻的相关性高于水华微囊藻.
\end{abstract}

关键词: 太湖;浮游植物; 重金属; CCA

\section{Seasonal variation and distribution characteristics of heavy metals in phytoplankton of dif- ferent parts of Lake Taihu}

\author{
WANG Yingxue ${ }^{1,2}$, WANG Peifang ${ }^{1,2}$, WANG Chao ${ }^{1,2}$, LIU Jiajia ${ }^{1,2}$ \& WANG Ruizhe ${ }^{1,2}$ \\ (1: Key Laboratory of Integrated Regulation and Resources Development on Shallow Lakes, Ministry of Education, Hohai Uni- \\ versity, Nanjing 210098 , P. R. China) \\ (2: College of Environment, Hohai University, Nanjing 210098, P. R. China)
}

\begin{abstract}
In recent years, the content of heavy metals in waste water which is discharged into Lake Taihu has been increasing continuously. In order to study the contamination status of heavy metals in phytoplankton of Lake Taihu, investigations were carried out in different parts of the lake in spring (April), summer(July) and winter(December), 2009. During the research, hierarchical cluster analysis (HCA) and Pearson correlation analysis were used to discuss the seasonal variation of heavy metals in phytoplankton in different parts of the lake. Canonical correspondence analysis (CCA) with dominant algae was applied to make a preliminary study of the relationship between heavy metals in phytoplankton and each alga. The results indicated that the sequence of heavy metals content in phytoplankton was $\mathrm{Zn}>\mathrm{Mn}>\mathrm{Pb}>\mathrm{Cu}>\mathrm{Ni}>\mathrm{Cr}>\mathrm{As}>\mathrm{Cd}>\mathrm{Hg}$. Besides, the seasonal variation of $\mathrm{Zn}, \mathrm{Cu}, \mathrm{Mn}$, $\mathrm{Pb}$ and $\mathrm{Ni}$ was obvious and there's strong dependency between $\mathrm{Cu}, \mathrm{Pb}, \mathrm{Ni}, \mathrm{Cr}$ and $\mathrm{Zn}$, which reveals their homology dramatically. By comparing different parts of Lake Taihu, the content of heavy metals in phytoplankton was discovered the highest in the North Bay and the content in east and center of the lake was lower than that in lakeshore district. Based on the CCA results, generally there's a positive correlation between heavy metals and dominant algae in spring, while a negative correlation in summer and winter on the contrary. What's more, it shows that heavy metals have the highest correlation with Cyanophyta and Chlorophyta and the lowest correlation with Cryptophyta. Among Cyanophyta, heavy metals have a higher correlation with Microcystis aeruginosa than those with Microcystis flos-aquae.
\end{abstract}

Keywords: Lake Taihu; phytoplankton; heavy metal; CCA

* 国家重点基础研究发展计划 “973” 项目(2010CB429006) 和国家水体污染控制与治理科技重大专项 (2012ZX07101008 ) 联合资助. 2014-04-09 收稿;2014-05-27 收修改稿. 王颖雪 (1989） , 女, 硕士研究生; E-mail: yingxuewendy@163.com.

** 通信作者;E-mail:pfwang2005@ hhu. edu. cn. 
太湖是我国的五大淡水湖之一, 位于社会经济发达的长三角地区 ${ }^{[1]}$. 近年来随着太湖流域工农业的迅 速发展, 煤、石油等化石燃料的消耗量增加, 大量含重金属的污废水排入湖体, 使得太湖的富营养化和重金 属污染日益严重 ${ }^{[24]}$. 浮游植物是湖泊生态系统的初级生产者, 处于食物链的最底端, 受重金属污染的影响 程度较大. 重金属在浮游植物的富集作用下, 通过食物链的累积和放大作用影响顶端生物 ${ }^{[5-6]}$, 破坏其正常 的生理代谢功能,威胁人类健康.

以往对太湖重金属的研究主要集中在水、沉积物的污染特征和分布状况上, 很少与浮游植物相结合. 本 文从这个角度出发, 在 2009 年 3 个季节调查资料的基础上, 分析了太湖不同湖区之间浮游植物中的重金属 含量变化特征, 并通过重金属与优势藻种的 CCA 分析对浮游植物重金属与各藻种关系进行初步探讨, 旨在 为太湖重金属污染的防控治理以及流域决策管理提供科学依据.

\section{1 材料与方法}

\section{1 采样时间与样点布设}

于 2009 年春季 $(4$ 月)、夏季 $(7$ 月)、冬 季(12 月) 3 个季节在太湖进行浮游植物的 样品采集. 根据太湖污染状况及沿岸地理 特征, 将太湖分为 8 个区域, 并根据所确立 的样点应对研究区域的多项调查指标有较 好代表性的原则 ${ }^{[7]}$, 共布设 34 个样点: 北 部梅梁湾 6 个、竺山湾 4 个、贡湖湾 9 个、西 部沿岸区 3 个、湖心区 6 个、南部沿岸区 2 个、东太湖 2 个、东部沿岸区 2 个, 覆盖全太 湖 (图 1).

\section{2 样品采集与处理}

1.2 .1 浮游植物的采集鉴定浮游植物采 用 $25^{\#}$ 浮游生物网 (网孔直径 $0.064 \mathrm{~mm}$ ) 在 表层至 $0.5 \mathrm{~m}$ 水深处呈 “ $\infty$ ” 形缓慢拖滤, 以 $20 \sim 30 \mathrm{~cm} / \mathrm{s}$ 的速度拖动 $1 \sim 3 \mathrm{~min}$ (网内 不得有气泡), 待网内多余水滤去, 全部标 本落人浮游网底管时, 打开底管活门, 将样 本装人干净的聚乙烯袋中密封, 运回实验 室冷冻干燥 ${ }^{[7]}$. 镜检样品用有机玻璃采水

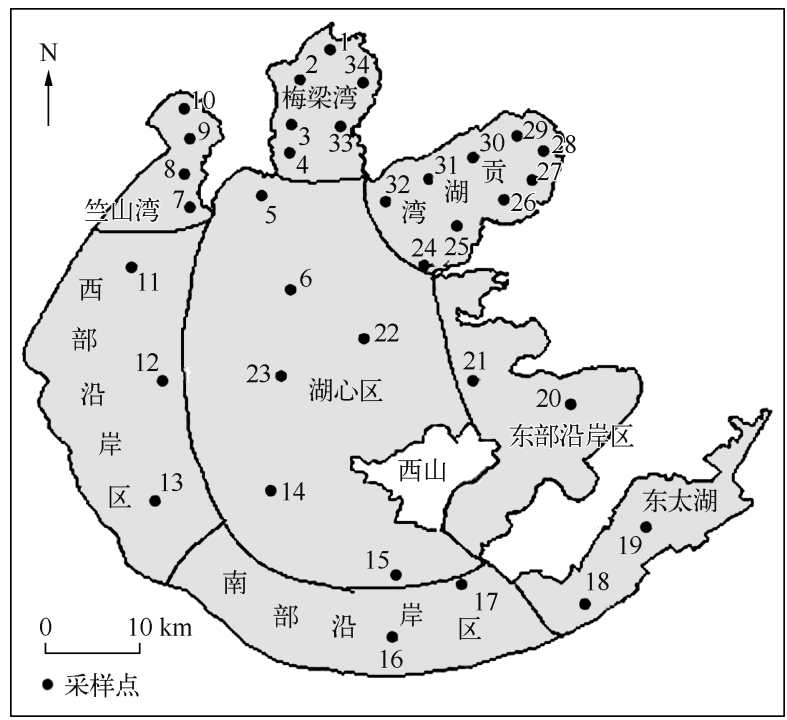

图 1 太湖湖区划分及采样点

Fig. 1 Regions and sampling sites in Lake Taihu 器在 $0.5 \mathrm{~m}$ 水深处取样 $1 \mathrm{~L}$, 并加 $1.5 \%$ 鲁哥试剂现场固定. 静置沉淀 $24 \mathrm{~h}$ 后浓缩至 $30 \mathrm{ml}$ 标本瓶中, 使用 $10 \times 40$ 倍光学显微镜鉴定种属 ${ }^{[8]}$.

1.2 .2 浮游植物中重金属的测定 将冷冻干燥后的浮游植物样品用玛瑙研钵研细, 过 100 目 $(0.149 \mathrm{~nm})$ 篎 后进行重金属元素的测定. 取 $0.2 \mathrm{~g}$ 样品置于聚四氟乙烯消解罐中, 采用 $\mathrm{HNO}_{3}-\mathrm{HF}^{-} \mathrm{H}_{2} \mathrm{O}_{2}$ 混酸微波消解, 冷却 后移至聚四氟乙烯烧杯中加人 $0.5 \mathrm{ml} \mathrm{HClO}_{4}$, 于 $200^{\circ} \mathrm{C}$ 电热板加热, 待样品蒸至近干时加人 $1.0 \mathrm{ml}$ 浓 $\mathrm{HNO}_{3}$, 定容摇匀 ${ }^{[9]}$. 用电感耦合等离子体发射光谱仪 (ICP-AES) 测定浮游植物中 $\mathrm{Cd} 、 \mathrm{~Pb} 、 \mathrm{Zn} 、 \mathrm{Ni} 、 \mathrm{Cu} 、 \mathrm{Mg} 、 \mathrm{Cr} 、 \mathrm{As} 、 \mathrm{Hg} 9$ 种重金属元素的含量.

\section{3 数据统计与分析}

1.3.1 聚类分析 利用 SPSS 17.0 对 34 个样点的浮游植物重金属进行聚类分析 ( HCA $)^{[10]}$. 聚类分析的实质 是建立一种分类方法, 在事先不知道样本数据类别的情况下, 将对象按照它们在性质上的亲疏程度进行自 动分类, 不同种类之间具有明显的区别 ${ }^{[11]}$. 本研究采用最常用的系统聚类法, 并建立聚类分析树状图, 对各 样点进行分类.

1.3.2 典型对应分析 利用 CANOCO 4.5 对浮游植物中重金属和优势藻种进行典型对应分析 (CCA) ${ }^{[12]}$, 
CCA 的基本思路是在对应分析的迭代过程中,每一步均与环境因子进行多元线性回归. 在所建立的二维排 序图中, 带箭头的射线代表重金属元素和优势藻种, 空心圆点代表采样点. 箭头所处的象限代表其与排序轴 的正负相关性, 而向量的长短则反映了其在主轴中的作用大小. 射线之间夹角的余弦值代表了它们之间的 相关性, 当夹角为 $90^{\circ}$ 时相关性最低 ${ }^{[13]}$.

\section{2 结果与分析}

\section{1 浮游植物中重金属含量的季节变化特征}

2009 年春、夏、冬 3 次调查的统计数据显示, 太湖浮游植物中所测的 9 种重金属含量呈现明显的梯度分 布: $\mathrm{Zn} 、 \mathrm{Mn} 、 \mathrm{~Pb}$ 所占的比例最大, 平均浓度在 $156.06 \sim 339.79 \mathrm{mg} / \mathrm{kg}$ 之间, 可达重金属总量的 $80.36 \%$; 其次 为 $\mathrm{Cu} 、 \mathrm{Ni} 、 \mathrm{Cr}$, 平均浓度在 $32.22 \sim 84.45 \mathrm{mg} / \mathrm{kg}$ 之间, 共占总量的 $18.44 \%$; $\mathrm{As} 、 \mathrm{Cd} 、 \mathrm{Hg}$ 的含量很低, 平均浓度 在 $0.83 \sim 6.07 \mathrm{mg} / \mathrm{kg}$ 之间, 只占到总量的 $1.20 \%$. 综合 3 个季节数据, 太湖浮游植物中重金属含量的大小顺 序为: $\mathrm{Zn}>\mathrm{Mn}>\mathrm{Pb}>\mathrm{Cu}>\mathrm{Ni}>\mathrm{Cr}>\mathrm{As}>\mathrm{Cd}>\mathrm{Hg}$ (表 1$)$.

表 1 太湖浮游植物中重金属含量

Tab. 1 Content of heavy metals in phytoplankton of Lake Taihu

\begin{tabular}{cccccc}
\hline 重金属 & 最大值 $/(\mathrm{mg} / \mathrm{kg})$ & 最小值 $/(\mathrm{mg} / \mathrm{kg})$ & 平均值 $/(\mathrm{mg} / \mathrm{kg})$ & 标准差 $/(\mathrm{mg} / \mathrm{kg})$ & 变异系数 \\
\hline $\mathrm{Zn}$ & 702.71 & 54.31 & 339.79 & 149.89 & 0.50 \\
$\mathrm{Mn}$ & 370.20 & 130.76 & 234.66 & 160.02 & 0.68 \\
$\mathrm{~Pb}$ & 376.29 & 36.92 & 156.06 & 81.23 & 0.52 \\
$\mathrm{Cu}$ & 206.00 & 17.23 & 84.45 & 53.28 & 0.63 \\
$\mathrm{Ni}$ & 87.17 & 17.69 & 50.96 & 11.14 & 0.22 \\
$\mathrm{Cr}$ & 62.25 & 8.99 & 32.22 & 7.56 & 0.23 \\
$\mathrm{As}$ & 12.77 & 1.36 & 6.07 & 2.52 & 0.42 \\
$\mathrm{Cd}$ & 4.98 & 2.18 & 4.04 & 1.11 & 0.27 \\
$\mathrm{Hg}$ & 1.05 & 0.68 & 0.83 & 0.20 & 0.25 \\
\hline
\end{tabular}

变异系数体现了数据间的平均离散程度. 太湖浮游植物中各重金属的变异系数均大于 $20 \%$ (表 1 ), 表明其季节变化特征明显. 在总量上表现为: 春季 > 冬季 > 夏季. 对于单个元素,除 $\mathrm{Ni}$ 在夏季的含量增加 外,其余各重金属的季节变化均与总趋势相同. 不同元素的季节变化幅度也不尽相同. Zn 浓度的变化幅度 最大,在夏季下降显著,总量低于 $\mathrm{Mn}$ 和 $\mathrm{Ni}$, 不再占绝对优势; $\mathrm{Cu}$ 的含量较低,但在冬季有很大提高; 而 $\mathrm{Pb}$ 浓度在夏季降幅较大, 冬季基本不变, 因此冬季 $\mathrm{Cu}$ 的总含量超过 $\mathrm{Pb} ; \mathrm{Mn}$ 浓度的降幅较大但远低于 $\mathrm{Zn}$, 于 夏季浓度超过 $\mathrm{Zn}$ 达到最大; $\mathrm{Ni}$ 在夏季的含量增加, 仅次于 $\mathrm{Mn}$; 其余重金属的季节变化幅度不大 (图 $2 \mathrm{a}$ ).

\section{2 浮游植物中重金属含量的空间变化特征}

太湖不同湖区浮游植物中的重金属含量存在显著差异, 在总量上表现为: 北部湖湾 > 沿岸湖区 $>$ 东太 湖和湖心区. 其中北部湖湾以梅梁湾浮游植物的重金属含量最高, 其次为贡湖湾; 沿岸湖区中南部湖区的浮 游植物中重金属含量最高; 以养殖业为主的东太湖和湖心区含量最低. 对于单个元素, Zn 在梅梁湾、贡湖湾 和南部沿岸区的含量均较高, 最低值出现在湖心区; Mn 在北部湖区的含量高于其它湖区, 其中以梅梁湾最 高, 其余湖区的含量差别不大; $\mathrm{Pb}$ 的最大值出现在西部沿岸区, 其次是贡湖湾, 最小值位于东太湖; $\mathrm{Cu}$ 在梅 梁湾最高, 南部沿岸区的比重也较大, 仅次于梅梁湾, 湖心区的含量最低; Ni 的最大值位于贡湖湾, 略高于沿 岸地区; $\mathrm{Cr}$ 在湖心区含量最低, 其它湖区差别不大; As 在西部沿岸和湖心区的含量小于其它湖区; $\mathrm{Cd}$ 和 $\mathrm{Hg}$ 在各湖区的差别不大 (图 $2 b$ ).

对太湖浮游植物 34 个样点的 9 种重金属进行聚类分析, 将点位分为 3 类. 第 1 类包括 $8 、 9 、 16 、 20$ 等点 位, 分别位于西部、南部、东部沿岸湖区以及北部竺山湾的部分湖区; 第 2 类包括 $2 、 24 、 27 、 33$ 等点位, 主要位 于北部重金属含量较高的梅梁湾和贡湖湾一带; 第 3 类包括 $6 、 14 、 17 、 23$ 等点位, 主要分布在东太湖和湖心 区, 这些点位的浮游植物中重金属含量较低; 1 号点离梅梁湾的人湖河道和人类活动区较近, 重金属含量很 高, 可归为第 2 类; 22 号点位于湖心, 重金属含量低, 可归为第 3 类 (图 3 ). 
a

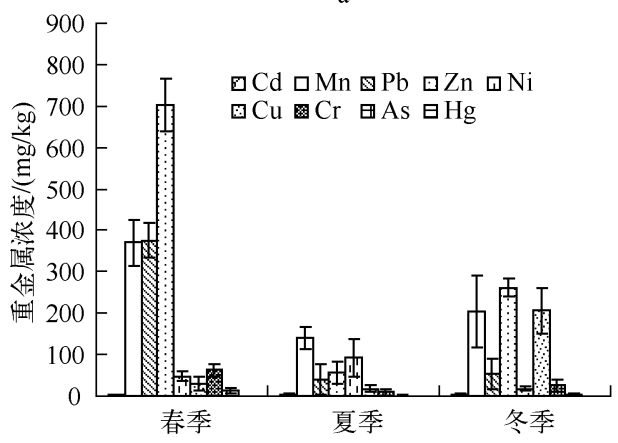

$\mathrm{b}$

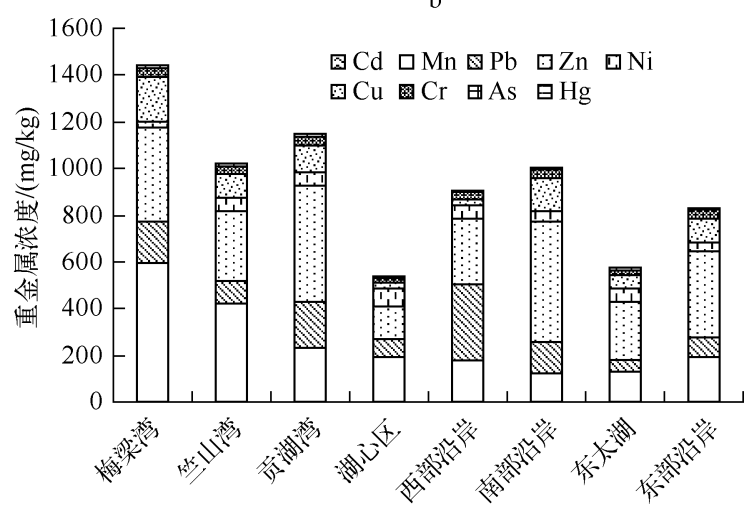

图 2 太湖浮游植物重金属含量的季节变化 (a) 和空间分布 (b)

Fig. 2 Seasonal(a) and spatial(b) variations of heavy metals in phytoplankton in Lake Taihu

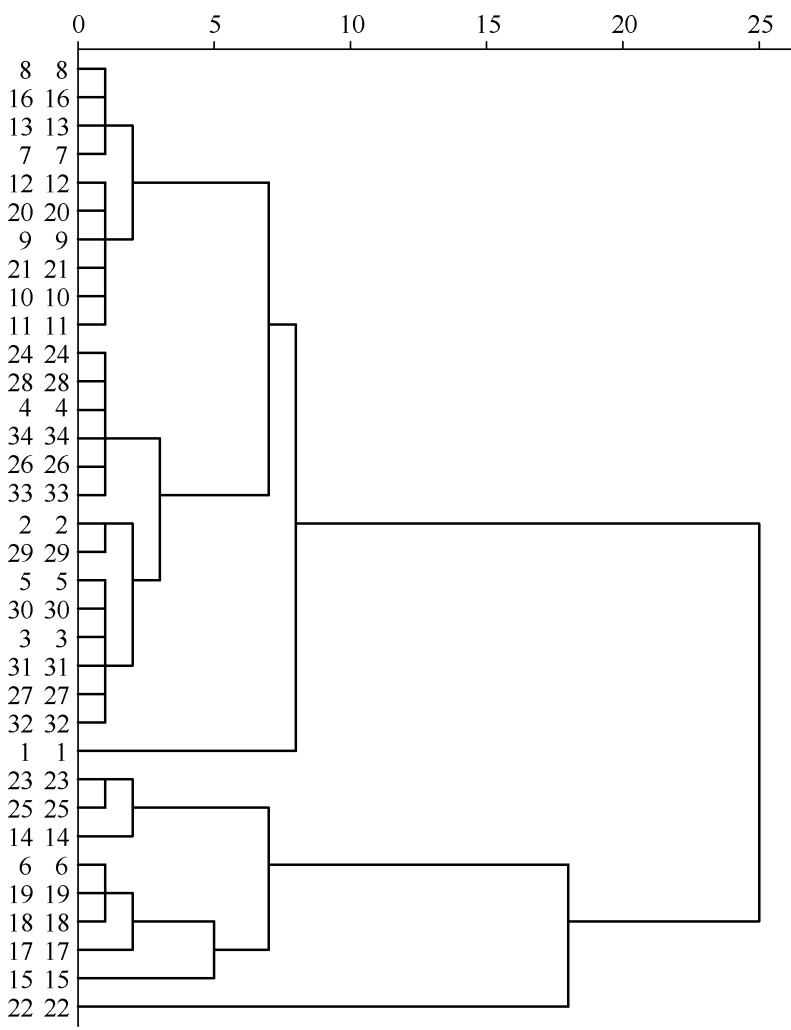

图 3 太湖浮游植物重金属聚类树状图

Fig. 3 HCA tree diagram of heavy metals in phytoplankton of Lake Taihu

为了进一步研究太湖浮游植物中重金属空间分布的相关性及其来源, 对 9 种重金属总量进行了 Pearson 相关分析. 由表 2 可以看出, $\mathrm{Zn}$ 和 $\mathrm{Cu} 、 \mathrm{~Pb} 、 \mathrm{Ni} 、 \mathrm{Cr}$ 之间的相关系数很高, 表明它们具有显著的同源性, 即具有 相似的污染源和污染程度. 其中 $\mathrm{Pb}$ 与 $\mathrm{Ni}$ 的相关系数相对较小, 但它与 $\mathrm{Zn}$ 和 $\mathrm{Cu}$ 的相关性较高, 与 $\mathrm{Cr}$ 的相关 性最高, 因此可推断 $\mathrm{Pb}$ 与其它 4 种重金属污染仍为同一来源,但污染程度略不相同. $\mathrm{Mn}$ 和 $\mathrm{Zn} 、 \mathrm{Cu} 、 \mathrm{~Pb} 、 \mathrm{Ni}$ 的 相关系数较高, $\mathrm{Hg}$ 和 $\mathrm{Zn} 、 \mathrm{As}$ 之间也存在一定的相关性. 
表 2 浮游植物中重金属含量的相关矩阵

Tab. 2 Correlation matrix of heavy metals in phytoplankton

\begin{tabular}{ccllllllll}
\hline 元素 & $\mathrm{Cd}$ & $\mathrm{Mn}$ & $\mathrm{Pb}$ & $\mathrm{Zn}$ & $\mathrm{Ni}$ & $\mathrm{Cu}$ & $\mathrm{Cr}$ & $\mathrm{As}$ & $\mathrm{Hg}$ \\
\hline $\mathrm{Cd}$ & 1 & & & & & & & & \\
$\mathrm{Mn}$ & -0.080 & 1 & & & & & & & \\
$\mathrm{~Pb}$ & -0.136 & $0.519^{*}$ & 1 & & & & & & \\
$\mathrm{Zn}$ & -0.103 & $0.424^{*}$ & $0.623^{* *}$ & 1 & & & & & \\
$\mathrm{Ni}$ & -0.218 & $0.423^{* *}$ & $0.357^{*}$ & $0.865^{* *}$ & 1 & & & & \\
$\mathrm{Cu}$ & -0.068 & $0.536^{* *}$ & $0.670^{* *}$ & $0.921^{* *}$ & $0.883^{* *}$ & 1 & & \\
$\mathrm{Cr}$ & 0.021 & 0.308 & $0.961^{* *}$ & $0.992^{* *}$ & $0.803^{* *}$ & $0.956^{* *}$ & 1 & & \\
$\mathrm{As}$ & 0.324 & 0.291 & -0.080 & 0.201 & 0.028 & 0.313 & 0.250 & 1 \\
$\mathrm{Hg}$ & 0.288 & -0.147 & 0.085 & $0.537^{* *}$ & -0.130 & 0.131 & 0.240 & $0.424^{*}$ & 1 \\
\hline
\end{tabular}

*表示显著相关 $(P<0.05) ; * *$ 表示极显著相关 $(P<0.01)$.

\section{3 浮游植物中重金属含量与藻种的关系}

通常浮游植物中重金属浓度主要与浮游植物的种类组成、生物量以及外界环境因子有关. 不同季 节、不同湖区浮游植物的优势种不同, 而不同种类的浮游植物对重金属的吸收情况也不尽相同, 因此 本文在 3 个季节调查资料的基础上, 选取全年常见优势种, 对浮游植物重金属含量与各藻种关系进行 初步探讨. 藻种的采样点与浮游植物重金属采样点相同, 覆盖太湖各湖区, 选取的优势种为蓝藻中的 铜绿微囊藻 (Microcystis aeruginosa)、水华微囊藻 (M. flos-aquae), 绿藻中的小球藻 (Chlorella vulgaris), 硅藻中的颗粒直链藻 (Aulacoseira granulata) , 隐藻中的尖尾蓝隐藻 (Chroomonas acuta) 和甲藻中的角甲 藻 (Ceratium hirundinella).

二维排序图中第一轴是约束性排序轴, 对响应变量的解释比例达 $40 \%$, 后三轴都是非约束性的, 解释比 例为 $26.4 \%$, 第一轴解释量大于第二轴. 春季, 从总体上看重金属与优势藻种含量呈正相关, 除尖尾蓝隐藻 外, 其余藻类均与重金属关系密切. 其中 $\mathrm{Ni}$ 与铜绿微囊藻的相关性高于水华微囊藻; $\mathrm{Pb} 、 \mathrm{Hg}$ 与小球藻, $\mathrm{Cu}$ 与 角甲藻均呈高度正相关; 而 $\mathrm{As}$ 与大部分藻类呈负相关. 第 III 象限的 $1 、 7 、 25$ 等点位主要与 $\mathrm{Ni} 、 \mathrm{Cu} 、 \mathrm{~Pb}$ 和蓝绿 藻的相关性较高, 大都分布在北部湖湾; 而沿岸湖区的点位主要分布在 II 、IV 象限, 与 Zn、Mn、Cd 的相关性较 高;6、15、22 等湖心区点位也分布在第 IV 象限, 与 Cd 的相关性最高 (图 4a).

夏季的二维排序图中第一轴对响应变量的解释比例达 $62.3 \%$, 第二轴的解释比例为 $16.3 \%$, 第一轴解 释量远高于第二轴. 从总体上看重金属与优势藻种含量呈负相关, 并与蓝绿藻和角甲藻关系密切. 其中 $\mathrm{Ni}$ 和 $\mathrm{Hg}$ 虽然与蓝绿藻和甲藻呈正相关, 但相关性不高, 其余重金属均与这 3 类藻呈负相关; 所有重金属均与 尖尾蓝隐藻呈负相关, 与颗粒直链藻呈正相关, 但这两种藻并不占主要因素. 点位在各象限的分布比较均匀 (图 4b).

冬季的二维排序图中第一轴对响应变量的解释比例为 $51 \%$, 第二轴的解释比例为 $13.7 \%$, 第一轴解释 量明显高于第二轴. 从整体上看重金属与优势藻种含量呈负相关, 并与蓝绿藻和硅藻的关系密切. 其中所有 重金属均与颗粒直链藻和尖尾蓝隐藻呈正相关; $\mathrm{Pb}$ 与角甲藻的相关性较高; 除 $\mathrm{Pb}$ 外所有重金属均与蓝绿藻 呈负相关. 沿岸湖区的 $11 、 13 、 16 、 21$ 点位于第 I 象限; $5 、 25 、 34$ 等北部湖湾的部分点位主要位于 II 、III象限, 与 $\mathrm{Zn} 、 \mathrm{Cu} 、 \mathrm{~Pb} 、 \mathrm{Mn}$ 以及蓝藻和硅藻的相关性较高 (图 4c).

\section{3 讨论}

水体中的重金属含量很低且分布不规律, 往往因气象水文条件以及人类排放等因素表现出较大的随机 性. 而在浮游植物中重金属容易得到积累并呈现出比较明显的分布特征 ${ }^{[14]}$. 太湖流域面积广阔, 连同进出湖 泊的 200 多个大小河道组成一个密如蛛网的水系. 由于人类经济活动的影响以及污染治理措施的不同, 各 湖区的生态环境差别较大, 浮游植物中重金属的含量分布也不尽相同 ${ }^{[15-16]}$. 


\section{1 浮游植物中重金属含量的季节变化特征}

2009 年对太湖的调查统计数据显示, 浮游植 物中重金属以 $\mathrm{Zn} 、 \mathrm{Mn} 、 \mathrm{~Pb}$ 占优势, 且季节变化幅度 较大, $\mathrm{Cu} 、 \mathrm{Ni} 、 \mathrm{Cr}$ 含量次之, 而 $\mathrm{As} 、 \mathrm{Cd} 、 \mathrm{Hg}$ 含量很 低, 季节变化不大. 陈璐璐等 ${ }^{[17]}$ 通过研究太湖水体 中典型的重金属污染及生态风险,认为随着电镀 和有色金属冶炼工业的快速发展, 大量含 $\mathrm{Zn} 、 \mathrm{Ni}$ 、 $\mathrm{Mn}$ 的污水排人太湖,合成橡胶工业所使用的稳定 剂会产生 $\mathrm{Zn} 、 \mathrm{~Pb}$ 和 $\mathrm{Cd}$, 开采冶炼和机械制造也会 排放含有 $\mathrm{Cu}$ 和 $\mathrm{Zn}$ 的废水, $\mathrm{Cr}$ 主要来源于铝盐生 产和皮革制造. 支田田等 ${ }^{[18]}$ 研究认为浮游植物中 $\mathrm{Zn}$ 的含量最高, 主要与周边污水的排放有关; $\mathrm{Pb}$ 污染的含量高不仅由于工业废水的影响, 还与农 业生产中的杀虫剂和化肥使用有关, 此外, 在太湖 上航行的船只通过汽油燃烧排放的废气也可以进 人水体中.

由于人为污染的重金属会以非残渣态的形式 存在, 容易受到外界条件和多种因素的影响, 因此 会产生季节波动 ${ }^{[19]}$. Wang 等 ${ }^{[20]}$ 认为,一般温度较 低时,浮游植物对重金属的吸附量随水温升高而 增加, 当达到一定温度后随水温升高而减小. 太湖 冬季到春季水温逐渐升高, 浮游植物对重金属的 吸附量不断增大, 而随着夏季水温升高到一定限 度时, 吸附量开始降低, 因此浮游植物中重金属的 季节变化表现为: 春季 $>$ 冬季 $>$ 夏季. 此外,蔡文 贵等 ${ }^{[21]}$ 通过分析考洲洋重金属污染水平与潜在生 态危害,认为夏季降水充沛,加上沿湖径流带人大 量富含氮、磷的冲淡水,对重金属起到了稀释和向 湖外转移的作用, 浮游植物的吸附量相应减少, 使 得夏季浮游植物中重金属的含量较低. 而本研究 中重金属 $\mathrm{Ni}$ 不符合此季节变化规律, 表明浮游植 物中重金属的含量是多因素影响的结果.

\section{2 浮游植物中重金属含量的空间变化特征}

通过对比太湖不同湖区浮游植物中重金属含 量, 发现北部湖湾的含量最高, 其中梅梁湾的浮游 植物受重金属污染最严重, 沿岸湖区高于湖心区 和东太湖. 任小龙等 ${ }^{[22]}$ 研究了太湖北部重金属分 布特征及潜在生态风险,认为北部湖湾离常州和 无锡最近, 人口稠密, 工农业发达, 周围分布着众 多冶炼厂、造纸厂以及电镀电池等化学产业, 大量 重金属通过望虞河、太滆运河等密集的人湖河流 排人湖内, 浮游植物中重金属的污染程度最高. 李 聪聪等 ${ }^{[23]}$ 通过分析梅梁湾重金属浓度的时空变 化,发现梅梁湾位于北部经济发达的无锡工业区,
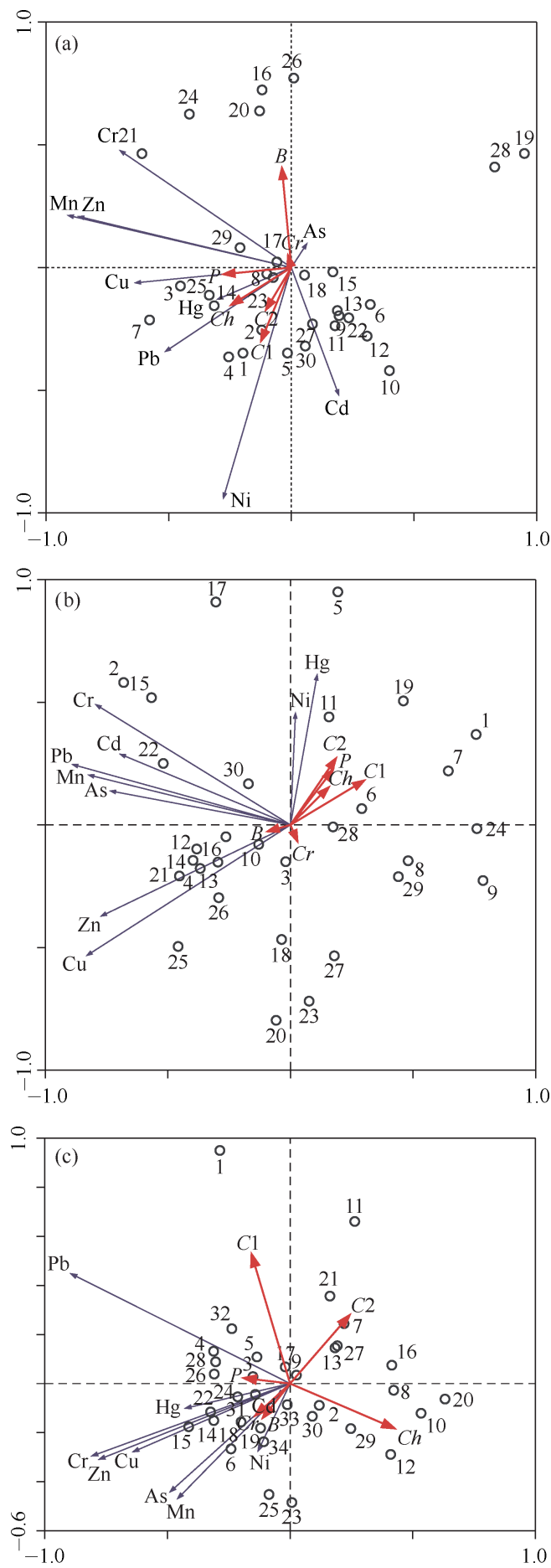

图 4 浮游植物中重金属与优势澡种含量的 CCA 分析: (a) 春季; (b) 夏季; (c) 冬季

$(C 1$ : 铜绿微囊藻; $C 2$ : 水华微囊藻; $C h$ : 小球藻; $B$ : 颗粒直链藻; $C r$ : 尖尾蓝隐藻; $P$ :角甲藻)

Fig. 4 CCA analysis of heavy metals in phytoplankton and dominant algae:(a) spring; (b) summer; 
周围 20 多家重点工业源每年可排放大量含重金属的未处理污水, 并通过直湖港和梁溪河汇人梅梁湾, 这也 是梅梁湾浮游植物中 $\mathrm{Zn} 、 \mathrm{Mn} 、 \mathrm{Cu} 、 \mathrm{Ni}$ 高于其它湖区的原因之一; 此外, 由于湖湾相对狭窄封闭, 与湖心区的交 换作用较差,重金属在湖湾区得到进一步累积.

Yan 等 ${ }^{[24]}$ 研究了冬季环太湖河流的重金属分布, 认为贡湖湾承接了来自苏州的部分污水, 但其同时也 是无锡的饮用水源地, 因此得到了一定程度的保护; 此外, 贡湖湾西南部远离城市, 水面开阔流动性较强, 且 与湖心区相连通, 有一定的自净能力, 因此浮游植物的重金属污染程度低于梅梁湾. 袁和忠等 ${ }^{[25]}$ 对太湖重金 属和营养盐污染进行了分析评价, 发现西南沿岸湖区分布着众多人湖河流和港口, 如新渎河、洋溪河、大浦 港等, 周边的工业废水排放以及人类活动的影响是浮游植物中重金属含量较高的主要原因. 但西南沿岸的 企业远不如北部区域密集, 污废水排放量也少于北部, 因此西南沿岸浮游植物中重金属的污染程度低于北 部湖湾. 白秀玲等 ${ }^{[26]}$ 研究认为湖心、东部湖区离常州和无锡较远, 周围企业较少, 受人类影响较小, 且湖区内 河流多为出湖河流, 浮游植物中重金属的污染程度较轻.

\section{3 浮游植物中重金属含量与藻种的关系}

浮游植物中重金属浓度的时空变化与浮游植物的种类和数量具有相关性. 李文君 ${ }^{[27]}$ 通过研究黄、东海 春季网采浮游植物中部分金属元素组成, 认为其分布规律受到浮游植物群落种类、数量以及陆源物质输人 等影响. 许昆灿等 ${ }^{[28]}$ 通过研究海洋环境中浮游植物对录的摄取规律, 认为某一区域内浮游植物中重金属浓 度主要受生物活性重金属浓度以及浮游植物生物量的影响.

通过 CCA 分析可以看出, 春季总体上重金属与优势藻种含量呈正相关, 而夏季和冬季二者呈负相关. 吴 建新等 ${ }^{[29]}$ 通过研究吕泗大洋港浮游植物群落与环境因子关系, 认为夏季充足的水量会稀释重金属的含量, 对藻类的毒性作用也相对降低, 加之沿岸大量汇人了富含 N、P 的废水使蓝藻暴发, 藻密度大幅增加, 因此该 季藻类中重金属量下降, 二者呈负相关性; 苏玉等 ${ }^{[30]}$ 分析了太湖武进港夏季和冬季浮游植物与环境因子的 关系, 认为冬季随着温度降低, 大量广温普生性的蓝绿藻数量剧减, 喜低温的硅藻成为优势种, 浮游植物在 数量上大幅下降, 但冬季水量较小、重金属浓度较高, 二者也呈负相关性; 春季是浮游植物的恢复期, 大部分 浮游植物开始增多, 重金属的浓度也随着水温和水量等因素开始升高, 加上某些重金属 (如 Fe、Zn 等) 在低 浓度时对浮游植物有促进作用 ${ }^{[31]}$, 二者在一定程度上呈正相关性.

浮游植物的种类数量不同, 其重金属含量也不尽相同. 三季中重金属与蓝藻和绿藻的相关性最高, 与隐 藻的相关性最低, 其中蓝藻中重金属与铜绿微囊藻的相关性高于水华微囊藻. Raize 等 ${ }^{[32]}$ 研究认为当生物体 暴露在含有重金属的溶液中时, 细胞壁首先与重金属离子接触, 细胞壁的结构和化学组成决定着生物体与 重金属离子相互作用的特性. 蓝藻在太湖中分布较广, 其微囊藻容易暴发形成水华, 对重金属有较强的耐受 性. Kleinübing 等 ${ }^{[33]}$ 研究认为其细胞壁带一定的负电荷, 具有较大的表面积和粘性, 可以提供多种官能团与 重金属离子结合, 此外蓝藻所特有的蓝藻颗粒体也是藻体内解毒系统的一部分. 绿藻中的小球藻也是太湖 常见优势藻种, 具有极强的繁殖能力, 汪苹等 ${ }^{[34]}$ 研究表明蓝绿藻不仅可以通过胞外多糖来络合重金属离子, 其细胞内也存在与重金属离子的结合位点. 但当重金属浓度过高时又会抑制藻类细胞正常代谢, 关于重金 属与藻类作用的机理仍有待进一步研究.

\section{4 参考文献}

[ 1 ] 孟顺龙,陈家长, 胡庚东等. 2008 年太湖梅梁湾浮游植物群落周年变化. 湖泊科学, 2010,22(4): 577-584.

[ 2 ] 焦 伟, 卢少勇, 李光德等. 环太湖主要进出河流重金属污染及其生态风险评价. 应用与环境生物学报, 2010,16 (4) :577-580.

[ 3 ] Jiang X, Wang W, Wang S et al. Initial identification of heavy metals contamination in Lake Taihu, a eutrophic lake in China. Journal of Environmental Sciences, 2012, 24(9):1539-1548.

[ 4 ] Yao SC, Xue B. Nutrients and heavy metals in multi-cores from Zhushan Bay at Lake Taihu, the largest shallow lake in the Yangtze Delta, China. Quaternary International, 2010, 226(1):23-28.

[ 5 ] Malik N, Biswas AK, Raju CB. Plankton as an indicator of heavy metal pollution in a freshwater reservoir of Madhya Pradesh, India. Bulletin of Environmental Contamination and Toxicology, 2013, 90(6):725-729.

[ 6 ] 浩云涛,李建宏. 椭圆小球藻 (Chlorella ellipsoidea) 对 4 种重金属的耐受性及富集. 湖泊科学,2001,13(2):158-162. 
[ 7 ] 金相灿, 屠清瑛. 湖泊富营养化调查规范. 北京: 中国环境科学出版社, 1990:239-241.

[8] 周凤霞,陈剑虹. 淡水微型生物图谱. 北京:化学工业出版社,2010.

[ 9 ] Wei B, Yang L. A review of heavy metal contaminations in urban soils, urban road dusts and agricultural soils from China. Microchemical Journal, 2010, $94(2)$ :99-107.

[10] Zafiriou P, Mamolos AP, Menexes GC et al. Analysis of energy flow and greenhouse gas emissions in organic, integrated and conventional cultivation of white asparagus by PCA and HCA: cases in Greece. Journal of Cleaner Production, 2012 , $29: 20-27$.

[11］蒋国毅,陈 超. SPSS 17 中文版统计分析典型实例精粹. 北京: 电子工业出版社,2010:161-167.

[12] Bagheri Bodaghabadi M, Salehi MH, Martínez-Casasnovas JA et al. Using Canonical Correspondence Analysis( CCA) to identify the most important DEM attributes for digital soil mapping applications. Catena, 2011, 86(1):66-74.

[13] Leps J, Smilauer P. Multivariate analysis of ecological data using CANOCO. London: Cambridge University Press, 2003.

[14] 周文涁,邱保胜. 藻类对重金属的耐性与解毒机理. 湖泊科学,2004,16(3) :265-272.

[15] Tao Y, Yuan Z, Xiaona H et al. Distribution and bioaccumulation of heavy metals in aquatic organisms of different trophic levels and potential health risk assessment from Lake Taihu, China. Ecotoxicology and Environmental Safety, 2012,81 : $55-64$.

[16] Mazej Z, Al Sayegh-Petkovsek S, Pokorny B. Heavy metal concentrations in food chain of Lake Velenjsko jezero, Slovenia: an artificial lake from mining. Archives of Environmental Contamination and Toxicology, 2010,58 (4) : 998-1007.

[17] 陈璐璐,周北海,徐冰冰等. 太湖水体典型重金属镉和铬含量及其生态风险. 生态学杂志,2011,30(10):2290-2296.

[18] 支田田,程丽华, 徐新华等. 藻类去除水体中重金属的机理及应用. 化学进展,2011,23(8):1782-1794.

[19] 王 坎,刘永定, 李敦海. 水华蓝藻生物质对 $\mathrm{Cu}$ 和 $\mathrm{Cr}$ 金属离子的生物吸附. 水生生物学报, 2011,35 (6) : 1056-1059.

[20] Wang NX, Zhang XY, Wu J et al. Effects of microcystin-LR on the metal bioaccumulation and toxicity in Chlamydomonas reinhardtii. Water Research, 2012, 46(2) :369-377.

[21] 蔡文贵,林 钦, 贾晓平等. 考洲洋重金属污染水平与潜在生态危害综合评价. 生态学杂志,2005,24(3):343-347.

[22] 任小龙,朱 玲, 姚 华等. 䇥山湖及太湖西沿岸北段的重金属分布特征及其生态风险评价. 水资源保护,2012,28 ( 5 ) $: 43-47$.

[23] 李聪聪, 成小英, 张光生. 梅梁湾重金属浓度的时空变化.上海环境科学, 2010, (5):185-191.

[24] Yan SW, Yu H, Li HL et al. Spatial patterns of dissolved heavy metal in surrounding rivers of Lake Taihu during dry seasons. Environmental Science and Technology, 2011, 11:3.

[25] 袁和忠,沈 吉,刘恩峰. 太湖重金属和营养盐污染特征分析. 环境科学,2011,32(3):649-657.

[26] 白秀玲,谷孝鸿,杨龙元. 东太湖水环境现状及保护对策. 湖泊科学, 2006,18(1):91-96.

[27] 李文君. 黄、东海春季网采浮游植物中部分金属元素组成研究 [学位论文]. 青岛: 中国海洋大学,2012.

[28] 许昆灿, 吴丽卿, 郑长春等. 海洋环境中浮游植物对采的摄取规律研究. 海洋学报: 中文版, $1986,1: 8$.

[29] 吴建新,李 强, 张 晴. 吕泗大洋港浮游植物群落与环境因子关系. 生态学杂志,2013,32(2):396-400.

[30] 苏 玉, 文 航,王东伟等. 太湖武进港区域浮游植物群落特征及其主要水质污染影响因子分析. 环境科学,2011, 32 ( 7 ) : 1945-1951.

[31] Biller DV, Bruland KW. Sources and distributions of Mn, Fe, Co, Ni, Cu, Zn, and Cd relative to macronutrients along the central California coast during the spring and summer upwelling season. Marine Chemistry, 2013, 155:50-70.

[32] Raize O, Argaman Y, Yannai S. Mechanisms of biosorption of different heavy metals by brown marine macroalgae. Biotechnology and Bioengineering, 2004, 87 (4) :451-458.

[33] Kleinübing SJ, Da Silva EA, Da Silva MGC et al. Equilibrium of Cu( II) and Ni( II) biosorption by marine alga Sargassum filipendula in a dynamic system: Competitiveness and selectivity. Bioresource Technology, 2011,102 ( 7 ): $4610-4617$.

[34] 汪 苹, 胡章立. 衣藻细胞的重金属结合特性及其抗性机制. 环境科学与技术, 2009,32(1):84-89. 